\title{
A experiência da criança nas relações entre aquisição da linguagem, fala e escrita
}

\author{
Fernanda Lopes BORTOLINI 『 \\ Universidade de Passo Fundo (UPF) \\ João Ricardo Fagundes dos SANTOS (1) \\ Universidade de Passo Fundo (UPF)
}

○

OPEN ACCESS

EDITADO POR

Raquel Freitag

AVALIADO POR

Giovane Fernandes Oliveira

SOBRE OS AUTORES

Fernanda Lopes Bortolini

Contribuiu com João Ricardo

Fagundes dos Santos. Papéis:

conceptualização, escrita -

rascunho original.

João Ricardo Fagundes

dos Santos

Contribuiu com Fernanda Lopes

Bortolini. Papéis:

conceptualização, escrita -

rascunho original, análise e

edição.

DATAS

Recebido: 24/07/2020

Aceito: 04/08/2020

Publicado: 14/08/2020

COMO CITAR

Bortolini, F. L.; Santos, J. R. F.

(2020).

A experiência da criança nas relações entre aquisição da linguagem, fala e escrita. Revista da Abralin, v. 19, n. 2, p. 1-5,

2020.

\section{RESUMO}

A mesa redonda aqui resenhada tematiza o uso da língua na aquisição da linguagem. Cada convidado desenvolve sua apresentação enfatizando um aspecto sobre a criança e o uso da língua: Lourenço Chacon expõe sobre a relação entre práticas de oralidade e de letramento em dados não convencionais de escrita em uma abordagem discursiva; Marlete Sandra Diedrich explana sobre aquisição, fala e experiência de significação, a partir da perspectiva enunciativa benvenistiana; Gabriela Maria de Oliveira-Codinhoto apresenta sobre orações relativas e aquisição da escrita, sob a ótica funcionalista. Com suas análises, que convergem na demonstração do funcionamento e da sistematização da língua em produções linguísticas iniciais, cada um com sua singularidade, os pesquisadores mostram as potencialidades dos estudos sobre a relação da criança com a língua.

\section{ABSTRACT}

The round table reviewed here focuses on the use of language in language acquisition. Each researcher develops his presentation emphasizing an aspect about the child and the use of language: Lourenço Chacon expounds on the relationship between oral and literacy practices in unconventional writing data, in a discursive approach; Marlete Sandra Diedrich explains about acquisition, speech and experience of meaning, in the benvenistian enunciative perspective; Gabriela Maria de Oliveira-Codinhoto presents on relative prayers and writing acquisition, in a functionalist perspective. With their analyzes, which converge in demonstrating the functioning and 


\section{REVISTA DA ABRALIN}

systematization of the language in initial linguistic productions, each with its uniqueness, the researchers show the potential of studies on the child's relationship with the language.

\section{PALAVRAS-CHAVE}

Aquisição da linguagem. Produções linguísticas iniciais. Fala e escrita.

\section{KEYWORDS}

Language acquisition. Initial linguistic productions. Speaking and writing.

A mesa redonda intitulada A criança e o uso da língua: fala, escrita e suas relações na aquisição da linguagem, realizada no dia 17 de julho de 2020, às 19h, compõe a vasta programação do evento Abralin Ao Vivo (Linguistis online). A mesa foi constituída por Loureço Chacon (Universidade Estadual Paulista), Marlete Sandra Diedrich (Universidade de Passo Fundo) e Gabriela Maria Oliveira-Codinhoto (Universidade Federal do Acre), sob a mediação de Giovane Fernandes de Oliveira (Universidade Federal do Rio Grande do Sul). Os convidados discorreram sobre o uso da língua e suas relações na aquisição da linguagem, enfatizando a constituição da criança como falante e escrevente, a partir das seguintes perspectivas teórico-metodológicas: discursiva, enunciativa e funcionalista. Os debatedores abordaram diferentes óticas teóricas para estabelecer diálogos sobre a experiência de amadurecimento da criança no uso da língua, tanto na fala quanto na escrita, cada um a partir de sua perspectiva, a partir da sistematização da língua em produções linguísticas iniciais.

Lourenço Chacon (Unesp) apresenta A relação fala/escrita em dados não-convencionais de escrita infantil, construindo uma potente explanação a partir de duas perguntas: dados não-convencionais de escrita infantil permitem levantar questões acerca das relações entre fala e escrita? Se sim, para quais questões da aquisição da escrita esses dados apontam? Para responder a tais questões, o pesquisador situa os espectadores em suas concepções sobre os conceitos de fala e escrita, assumindo a perspectiva de que as práticas orais e as práticas letradas não se desenvolvem isoladas, de modo que a constituição do sujeito como falante e como escrevente se dá, precisamente, pelo seu atravessamento por diferentes práticas de oralidade e de letramento. Nessa perspectiva, Chacon apresenta a ideia de que se pode olhar para tal fenômeno, de um lado, a partir de dados de fala, observando-se os indícios de atravessamento do sujeito por práticas de oralidade e de letramento; e, de outro lado, a partir de dados de escrita, olhando-se igualmente práticas de letramento e de oralidade constitutivas do sujeito. Para elucidar essas concepções, o pesquisador apresenta a análise de um corpus interessante, observando a relação entre fala e escrita a partir de dados de escrita infantil. Seu ponto de vista analítico advém de um grupo de produções e estudos dele mesmo e de outros pesquisadores, sobre fenômenos que fogem às convenções em relação a pontuação, segmentação de palavras e ortografia. A análise revela que dados não convencionais da escrita infantil 


\section{REVISTA DA ABRALIN}

permitem levantar questões acerca das relações entre escrita e fala, pois esses dados indiciam o trânsito do escrevente simultaneamente por práticas de oralidade e letramento, assim como conflitos do escrevente sobre o que deve orientar sua prática escrita. Por fim, a análise revela a historicidade e a subjetividade constitutiva do sujeito escrevente.

Marlete Sandra Diedrich (UPF), com o título A aquisição da linguagem: uma experiência de significação, contribuiu à discussão enfocando o viés da aquisição da linguagem como uma experiência de significação. Para construir sua explanação, a convidada apresenta três pontos axiomáticos: 1) A criança fala com outros que falam; 2) A criança se constitui como falante de uma língua; 3) A criança apreende o mundo por meio da fala. A pesquisadora mobiliza a perspectiva enunciativa de Émile Benveniste e a perspectiva aquisicional enunciativa de Carmem Luci da Costa Silva para construir sua teorização e sua análise, convocando aspectos da fala e da constituição da criança como falante. Diedrich afirma que tais princípios teóricos iluminam as discussões sobre a aquisição da linguagem e que, a partir dos estudos acerca da enunciação, com foco no simbólico da língua, torna-se possível analisar o despertar da consciência da criança no meio social, apropriando-se da língua para viver suas experiências de significação com outros sujeitos via discurso. Mobilizando esses conceitos norteadores de sua análise, Diedrich convoca um belo corpus, com dados de linguagem das crianças Lulu e Antônia, interrogando esses dados na busca de entender como, a partir de produções linguísticas, cada criança se relaciona com a língua e vivencia sua experiência de significação. A partir disso, a pesquisadora analisa dados de aquisição de fala da criança Lulu, na relação com sua irmã Antônia, em dois recortes. Tais dados explicitam que, se "nós falamos com outros que falam", as crianças também o fazem. Lulu, com seis meses, no primeiro recorte do corpus, é convocada pela irmã mais velha a se marcar e participar do discurso; no segundo recorte, já com um ano e meio de idade, Lulu assume formas que se assemelham com formas linguísticas e agora já é capaz de convocar sua irmã mais velha Antônia para a cena enunciativa, o que ilustra a faculdade humana de simbolizar. Além disso, a análise do corpus revela o princípio da subjetividade, pois a criança vai assumir seu lugar no mundo pela linguagem e pela vivência de uma língua que a introduz como indivíduo na sociedade, conforme Diedrich mostra nos recortes; e também o princípio da referência, pois é na vivência de situações no simbólico da língua que a criança apreende o mundo em que vive. A pesquisadora conclui revelando que a análise dos dois recortes permite afirmar que, na relação com o outro e com sua maneira particular de estar na língua, a criança apreende o mundo e se manifesta na realização dessa língua na fala.

Gabriela Maria de Oliveira-Codinhoto (UFAC) potencializa a discussão com a fala intitulada As orações relativas e a aquisição da escrita: uma análise funcionalista de textos infantil. A pesquisadora assume a perspectiva de cunho funcionalista, sobretudo a de vertente holandesa, para analisar textos escritos por crianças. Ela apresenta, como corpus, textos extraídos do banco de dados oriundo de trabalhos do Grupo de Pesquisa Estudos sobre a Linguagem (Unesp/CNPq), liderado por Lourenço Chacon, selecionando textos de dois alunos, cuja evolução observa e acompanha durante o ensino 


\section{REVISTA DA ABRALIN}

fundamental I, isto é, da primeira até a quarta série ${ }^{1}$, o que configura a sua como uma pesquisa de abordagem longitudinal. Além disso, define como metodologia analítica um percurso que registra a frequência de orações relativas nos textos e a análise da composição textual global. Ancorada na perspectiva funcionalista, Oliveira-Codinhoto assume algumas noções importantes à sua análise, tais como língua, aquisição, escrita, e orações relativas. Definidos tais conceitos-chave, a pesquisadora apresenta uma bela análise do corpus selecionado, revelando hipóteses explicativas sobre a frequência geral das orações relativas em textos de crianças. Ela analisa os textos selecionados enfocando extensão, tipo de oração, tipo de contexto e estratégias de composição textual, bem como comparando as generalizações entre os textos dos dois alunos e analisando textos com propostas distintas e com as mesmas propostas. A partir dessa análise minuciosa, a pesquisadora conclui que os alunos evoluíram no decorrer de suas experiências de escrita, já que, no início, predominavam enunciados curtos, orações truncadas e o mecanismo de justaposição; já na quarta série, produziam enunciados longos, sentenças complexas, tendo um dos alunos mobilizado 17 orações relativas. Isso evidencia, portanto, que nas primeiras produções a relação do escrevente com a interação é bastante imediata, diferentemente de nas produções finais, em que os dados revelaram maior preocupação com o estabelecimento do contexto interacional, ampliando o estatuto informacional e apresentando o aparecimento de estruturas linguísticas mais complexas.

A discussão acerca do uso da língua na aquisição da linguagem, na mesa redonda aqui resenhada, dá-se na medida em que a exposição de Chacon abre a discussão evidenciando a relação entre práticas de oralidade e de letramento, para, em seguida, Diedrich apresentar mais detalhes dessa relação com dados de fala, e Oliveira-Codinhoto finalizar com dados de escrita. Nesse sentido, percebem-se alguns pontos interessantes de convergência entre as apresentações:

- Relações entre fala e escrita: as práticas de oralidade e letramento estão entrelaçadas e ambas deixam marcas no discurso das crianças, fator evidenciado na análise inicial e confirmado nas outras duas.

- Cada criança se marca no discurso a sua maneira: as práticas discursivas infantis são resultado das novas experiências no mundo, na interação com os pares, que amadurece com o passar do tempo na singularidade de cada sujeito.

- A criança se insere no mundo via língua: seja por práticas de oralidade ou de letramento, seja na fala ou na escrita, a criança ocupa seu espaço no mundo por meio do discurso, no uso da língua.

- A beleza no discurso das crianças: tanto os pesquisadores em suas apresentações quanto o público espectador nos comentários pelo chat ressaltaram como é encantador

${ }^{1}$ A pesquisa trabalha um corpus coletado entre os anos de 2001 a 2004, com dados a partir da organização antiga do Ensino Fundamental, composto de "séries". 


\section{REVISTA DA ABRALIN}

observar, por meio de dados de linguagem de crianças, o processo de inserção do indivíduo na língua e a evolução da sua relação com a linguagem.

Apesar de assumirem abordagens teórico-analíticas diferentes e consistirem em pesquisas que advêm de diferentes regiões do Brasil, as três explanações mostraram como é complexa a maneira com que acriança se relaciona com a língua e como essa relação evolui no decorrer da historicidade de experiências discursivas da criança. A discussão nesta mesa trouxe relevantes contribuições para os estudos sobre produções linguísticas iniciais e sobre a relação criança/língua, que é, como mencionado pelo mediador e pelos apresentadores, sempre desafiadora e fascinante.

\section{REFERÊNCIAS}

A criança e o uso da língua: fala, escrita e suas relações na aquisição da linguagem. Mesa redonda apresentada por Lourenço Chacon, Marlete Sandra Diedrich, Gabriela Maria de Oliveira-Codinhoto [s.l., s.n.], 2020.1 vídeo (2h 01min 35s). Publicado pelo canal da Associação Brasileira de Linguística. Disponível em: https://www.youtube.com/watch?v=fP2o-hF7jtg\&t=2012s. Acesso em: 20 jul. 2020. 